\title{
Clinical evaluation and pattern of symptoms in colorectal cancer patients
}

\author{
Marianne Regina Silva Potengy de MELL0 ${ }^{1}$, Silmara Fernandes MOURA', \\ Camila Drumond MUZI $^{2}$ and Raphael Mendonça GUIMARÃES ${ }^{3}$
}

Received: 2 October 2019 Accepted: 20 February 2020

\begin{abstract}
Background - Colorectal cancer is the third most common type of cancer in the world and the increased survival of the colorectal cancer population is very significant. Thus, it becomes relevant to study the symptoms associated with the progression of the disease and treatment, for proper clinical management. Objective - To describe the clinical and epidemiological profile of colorectal cancer patients and to identify the most prevalent signs and symptoms patterns. Methods - Cross-sectional study evaluating the prevalence of symptoms in 348 colorectal cancer patients admitted to a referral oncology hospital. We applied MSAS-BR scale and, through factor analysis with principal componente analysys, we performed the grouping of symptoms. Results - There was a predominance of men, aged 60 years or older, married, white, with high school, moderately differentiated tumor, stage III/IV disease, colon cancer and no distant metastasis. The most prevalent symptoms were weight loss $(67.53 \%)$ and the least prevalent were mouth sores $(2.01 \%)$. The groupings of symptoms established were "fatigue and psychic symptoms", "gastrointestinal symptoms", "self-perceptive symptoms" and "general symptoms", which described $80 \%$ of the symptoms presented. Conclusion - We evidenced the importance of identifying these symptoms clusters in order to improve strategies for clinical management in patients with colorectal cancer.
\end{abstract}

HEADINGS - Colorectal neoplasms. Symptom assessment. Quality of life.

\section{INTRODUCTION}

Colorectal cancer (CRC) is the third most common cancer in the world and represents the leading cause of mortality in many countries, especially in the most developed ones ${ }^{(1)}$. Importantly, it also has an increased incidence in developing countries ${ }^{(2)}$. It is estimated that in 2018 there were 1,849,518 new cases of the disease worldwide, representing $10.2 \%$ of all new cancers. In addition, the number of people who died from this cancer was 880,792 , representing $9.2 \%$ of all cancer deaths in the same year ${ }^{(3)}$. In Brazil, in turn, it is estimated that there are 17,380 new cases of colorectal cancer in men and 18,980 in women for each year of the 2018-2019 biennium ${ }^{(4)}$. Finally, the average five-year survival in Brazil has increased for this location, ranging from $44.5 \%$ in the previous period to $48.3 \%$ in the most recent period ${ }^{(5)}$.

There is two types of CRC: hereditary and sporadic, and the second of it is the most prevalent, and linked to the accumulation of lifelong mutations ${ }^{(6)}$. There are several evidences that lifestyle, especially diet and physical inactivity, are risk factors for sporadic colorectal cancer ${ }^{(2)}$. Classically, the disease mainly affects people over the age of 50 . Therefore, the screening from this age is recommended $^{(7)}$. Moreover, CRC may be asymptomatic at diagnosis or may present symptoms associated with local tumor growth ${ }^{(8)}$.

Doctors and researchers generally recognized multiple symptoms separately and focus their researchers into isolated symptoms. However, Aktas ${ }^{(9)}$ observed that some clusters symptom could have common mechanisms, and proposed a study about clusters that revolutionized symptom management in cancer patients. Thus, the concept of cluster symptom characterizes them as two or more concomitant symptoms that form a stable group and are relatively independent of other groupings, supported by the presence of clinical and statistical relevance, allowing a more complete description of symptom grouping in a specific context ${ }^{(10)}$.

Symptoms in cancer patients vary according to a combination of factors such as cancer type, cancer diagnosis and stage, treatment modalities used and characteristics inherent to the individual, such as presence and type of comorbidities, psychosocial variables and the biological context $t^{(11)}$.

With the increase in the incidence of colorectal cancer and the advancement of the techniques used in its treatment, surviving is more likely to achieve among patients who was treated ${ }^{(12)}$, and this population group tends to increase, with greater or lesser occurrence of symptoms, according to the stage and treatment ${ }^{(13,14)}$. That said, the objectives of the present study is to characterize the pattern of symptoms in patients with colon and rectal cancer.

\section{METHODS}

This is a cross-sectional study which used a data set on the prevalence and treatment of symptoms among colorectal cancer patients treated at Brazilian National Cancer Institute (INCA), the national reference cancer treatment unit in the country.

The sample included 348 adult patients admitted to the HCI / INCA abdominal-pelvic surgery service between 2016 and 2018,

Declared conflict of interest of all authors: none

Disclosure of funding: Conselho Nacional de Desenvolvimento Científico e Tecnológico (CNPq) - Bolsas de Iniciação Científica

Research performed at: Fundação Oswaldo Cruz. Escola Politécnica de Saúde Joaquim Venâncio.

1 Universidade Federal do Estado do Rio de Janeiro, Escola de Medicina e Cirurgia, Rio de Janeiro, RJ, Brasil. ${ }^{2}$ Instituto Nacional de Câncer José Alencar Gomes da Silva, Rio de Janeiro, RJ, Brasil. ${ }^{3}$ Fundação Oswaldo Cruz, Rio de Janeiro, RJ, Brasil.

Corresponding author: Raphael Mendonça Guimarães. E-mail: raphael.guimaraes@fiocruz.br 
equivalent to $82 \%$ of patients admitted during this period. We included patients aged at least 18 years old who had colorectal cancer regardless of staging. Patients who had cognitive disorders assessed through the mini-mental examination or conditions that could compromise the veracity of the responses, such as neoplasia or metastasis to the CNS, were excluded from the medical records.

We performed data collection using the Memorial Symptom Assessment Scale (MSAS-BR), after prior information on the research objectives, agreement to participate in the study and signing of the free and informed consent form as an individual interview. Additional data were collected using a form prepared by the authors, which included sociodemographic and clinical data such as age, gender, marital status, educational level, race, primary diagnosis and presence of metastasis, use of devices and place of treatment (outpatient and inpatient).

The Memorial Symptom Assessment Scale (MSAS) is a 32item assessment tool designed to measure the prevalence and the three associated characteristics (frequency, intensity, and distress) of the physical and psychological symptoms experienced by cancer patients in the week prior to the interview. Thus, targeted interventions can be proposed to ensure improvement in patients' quality of life ${ }^{(15)}$. MSAS-BR has good results for reliability and validity in the cancer population, as described in previous studies, with satisfactory reliability in test-retests and weighted kappa index values obtained between 0.69 and 0.96 . When a symptom is experienced, the score for it is determined by the average intensity, frequency and discomfort scores, or when applicable, only by the intensity and distress scale ${ }^{(15,16)}$. It's important to mention that we approached patients at times when they were not vulnerable or in a situation that did not compromise the decision to participate in the study.

Patients were selected after the clinical staff of the National Cancer Institute's abdominal and pelvic surgery service identified the subjects eligible for the study. After this, all patients have been approached after getting basic information from their medical records. We interviewed them in a moment that it couldn't disturb clinical team examination or family visiting. It's important to highlight that most of patients were in at postoperative phase, even for evaluating the extension of disease or performing the treatment. Most of them had advanced disease, so that the diagnostic accuracy of the tumor (colon or rectum) was low at the time of investigation.

We considered means and standard deviations of symptom score to identify commonly reported symptoms. To identify symptoms that tended to occur together, we used Spearman correlations between symptom pair scores. Then, bivariate analyzes of the relationships between symptom scores and clinical and demographic variables were based on one-way analysis of variance (ANOVA) and statistically significant results were reported. As an additional measure, corresponding nonparametric analyzes were also performed using Kruskal-Wallis tests ${ }^{(17)}$.

Symptom clusters were obtained using Principal Component Analysis (PCA) and Exploratory Factor Analysis (EFA). To examine any interrelationships between symptoms at each follow-up time point, principal component analysis was performed with Varimax rotation. This analytical method groups variables (symptoms) together to form a "component" (cluster), identifying which variables correlate with each other in a distinct pattern ${ }^{(17,18)}$. The highest load factor score determines the attribution of symptoms to clusters. It is noteworthy that this is the most commonly used analytical method in oncology symptom cluster research in international research. Then, the maximum likelihood method was then applied to multivariate normal data to measure the covariance between symptoms. Together, these two methods identify and determine the items (symptoms) that belong to each cluster. The SPSS v.24 statistical package was used for analysis.

Regarding the ethical aspects of this research, the study complied with the ethical and legal specifications of resolution no. 466/12 of the National Health Council/Ministry of Health, which regulates research involving human beings. Therefore, this work is authorized by INCA's Ethics and Research Committee, through its consubstantiated opinion number 863.339, not involving conflicts of interest.

\section{RESULTS}

The epidemiological profile found for the population with colorectal cancer studied was mostly male, aged 60 years or older, married, white and had high school education. They presented as predominantly colonic tumors, moderately differentiated, with stages III/IV and without distant metastases. Four clusters of colorectal cancer-related symptoms were identified: 1) fatigue and psychic symptoms; 2) gastrointestinal symptoms; 3) self-perceptive symptoms; and 4) general symptoms. The number of patients interviewed was 348 , of which $55.36 \%(\mathrm{n}=193)$ were male and $70.98 \%$ $(n=247)$ were 60 years or older. Among the patients, $64.77 \%(n=225)$ were married, $62.67 \%(\mathrm{n}=218)$ declared themselves white, $50.42 \%$ $(n=175)$ had high school, 61.18\% $(n=213)$ had a moderately differentiated tumor, $54.88 \%(\mathrm{n}=191)$ had stage III/IV disease, $61.59 \%$ $(n=214)$ had colon cancer and 60.63\% $(n=211)$ had no distant metastasis diagnosed at the time of the interview (TABLE 1).

TABLE 1. Clinical and demographic characteristics of study sample. $(\mathrm{n}=348)$

\begin{tabular}{lcc}
\hline Variable & $\mathbf{n}$ & $\%$ \\
\hline Sex & & \\
Male & 193 & 55.36 \\
Female & 155 & 44.64 \\
Age & & \\
$\quad$ Less than 60 years & 101 & 29.02 \\
60 years and more & 247 & 70.98 \\
Marital status & & \\
Single & 75 & 21.57 \\
Married & 225 & 64.77 \\
Widow & 47 & 13.60 \\
Race & & \\
White & 218 & 62.67 \\
Black & 130 & 37.33 \\
Literacy & & \\
Illiteracy/Elemental & 132 & 37.84 \\
High School & 175 & 50.42 \\
Higher education & 41 & 11.74 \\
Tumor differentiation & & \\
$\quad$ Well differentiated & 31 & 8.77 \\
Moderately differentiated & 213 & 61.18 \\
Poorly differentiated & 36 & 10.37 \\
Stage & & \\
I/II & 157 & 45.12 \\
III/IV & 191 & 54.88 \\
Site & & \\
Colon & 214 & 61.59 \\
Rectum & 134 & 38.41 \\
Yetastasis & & \\
Nos & 137 & 39.37 \\
\hline$\quad$ & & 60.63 \\
\hline
\end{tabular}


The most prevalent symptoms in the sample were weight loss $(67.53 \%)$, pain $(56.61 \%)$, dry mouth $(53.45 \%)$, concerns $(52.30 \%)$, and panning $(47.70 \%)$.). On the other hand, the least prevalent symptoms were cough $(11.49 \%)$, problems urinating $(10.92 \%)$, difficulty swallowing $(9.77 \%)$, difficulty concentrating $(6.03 \%)$ and wounds in the mouth $(2.01 \%)$. The average of items in the frequency category ranged from 1.74 (mouth sores) to 2.89 (stuffing); in intensity the range was from 1.43 (difficulty concentrating) to 2.38 (constipation); and uncomfortably from 1.82 (cough) to 3.60 ("I don't look the same anymore") (TABLE 2).
As in the original instrument, it should be noted that in the MSAS-BR eight of the 32 items - such as mouth sores, hair loss and weight loss - do not appear in the frequency category because they are continuously found in the course of the disease, and not sporadic, as with the others.

When performing the multivariate analysis in the statistical package, the rotation presented in the matrices presented the grouping distribution presented in TABLE 3. Thus, the final result showed four groups of symptoms, classified as 1) fatigue and psychic symptoms; 2) gastrointestinal symptoms; 3) self-perceptive

TABLE 2. Description of symptoms in colorectal cancer patients $(n=348)$.

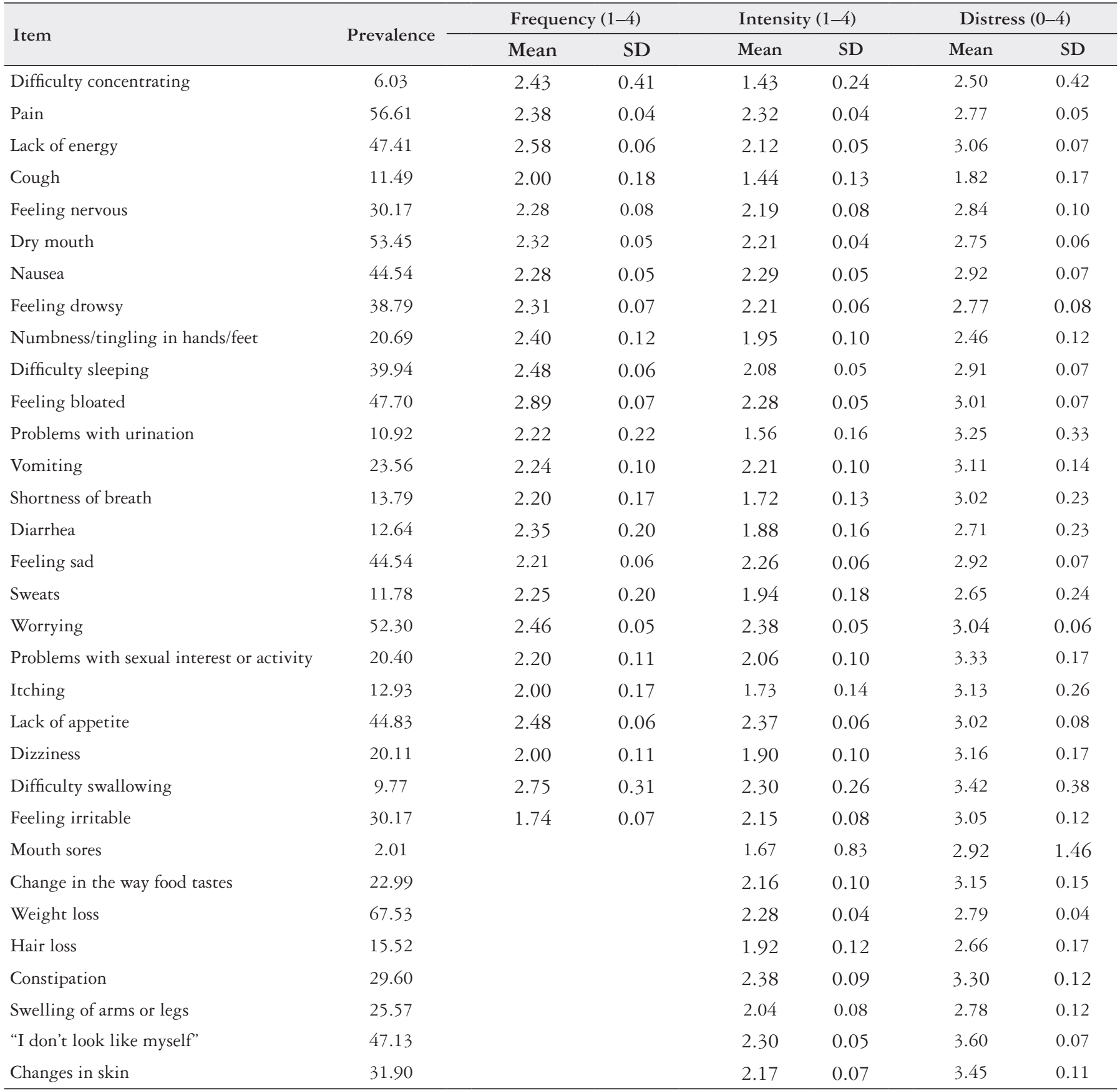


symptoms; and 4) general symptoms. Each grouping of symptoms has good discriminatory capacity, represented by the eigenvalue. The group "fatigue and psychic symptoms" together describe $48.22 \%$ of the symptoms in colorectal cancer patients. The groups "gastrointestinal symptoms", "self-perceptive symptoms" and "general symptoms" describe, respectively, 15.34\%, 8.04\% and $6.87 \%$ of symptoms in patients with CRC. By uniting the four groups formed, there is a $78.47 \%$ characterization of symptoms presented in patients with colorectal cancer (TABLE 3).

\section{DISCUSSION}

Colorectal cancer (CRC) patients may face a number of challenges during their treatment. In general, throughout treatment and for some time after its completion, survivors may experience multiple moderate to severe physical symptoms, including diarrhea, flatulence, changes in the frequency of bowel movement and urination, abdominal pain, nausea and vomiting, and fatigue. Although there is some consensus on time since treatment and the influence of certain factors such as staging, age and metastasis on symptoms in colorectal cancer survivors, there is limited evidence and information on the full extent of colorectal cancer symptoms and survival are fragmented ${ }^{(19)}$. For this reason, the study of symptoms has gained notoriety in recent years, especially from techniques that seek to qualify the description of its occurrence and intensity ${ }^{(20)}$.

Early symptom control can help prevent complications, and especially minimize loss of quality of life, for good clinical follow-up. In fact, the occurrence of multiple independent symptoms alters the individual's functional capacity, treatment effects and quality of life when their management is inadequate. Omran et al. ${ }^{(21)}$ pointed out that symptoms such as pain, dry mouth, cough, lack of appetite, drowsiness, difficulty swallowing, difficulty concentrating, concerns, lack of energy, dizziness, sadness and irritation are very relevant predictors of quality of life. life ${ }^{(22.23)}$. However, cancer symptoms and their treatment may coexist in different symptom groups.

Several studies indicate the association between colorectal cancer and changes in mental health, such as anxiety and depres$\operatorname{sion}^{(24-26)}$. This relationship may be influenced by specific diagnosis, disease staging, gender and age. The prevalence of depression ranges from $13 \%$ to $57 \%$ in CRC patients due mainly to the low 5 -year survival rate, but also because of the use of colostomy and the effects of chemotherapy, which promote a significant reduction in the quality of life of patients ${ }^{(21,27)}$. The use of colostomy, for example, generates a great social impact on the patient's life and may be associated with reduced mental health ${ }^{(26)}$.

With regard to fatigue, it is recognized that cancer-related fatigue $(\mathrm{CRF})$ is one of the most frequently reported symptoms in cancer survivors. However, despite changes in body composition, with progressive deterioration of physiological functions and metabolic processes causing a decline in adaptive capacity, fatigue is often associated with psychological symptoms ${ }^{(27)}$ and, therefore, it is reasonable to assume that all these symptoms remain in place at the same grouping. Thus, in the course of treating patients with $\mathrm{RCC}$, it is advisable to evaluate depression and anxiety and, if necessary, refer for further diagnosis and treatment.

On the other hand, the group of "gastrointestinal symptoms" also presented significant explanatory variance value (15.34\%). Marventano et al. ${ }^{(23)}$ highlighted that several symptoms that occur due to cancer localization and staging, such as diarrhea, fecal incontinence, constipation, fatigue and loss of appetite are also
TABLE 3. Factorial Matrix for the 4 Cluster Model in Colorectal Cancer Patients $(n=348)$.

\begin{tabular}{|c|c|c|c|c|c|}
\hline \multirow[b]{2}{*}{ Cluster } & \multirow[b]{2}{*}{ Symptoms } & \multicolumn{4}{|c|}{ Factorial load } \\
\hline & & $\begin{array}{c}\text { Factor } \\
1\end{array}$ & $\begin{array}{c}\text { Factor } \\
2\end{array}$ & $\begin{array}{c}\text { Factor } \\
3\end{array}$ & $\begin{array}{c}\text { Factor } \\
\quad 4\end{array}$ \\
\hline \multirow{9}{*}{ 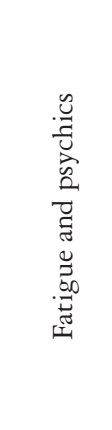 } & $\begin{array}{l}\text { Difficulty } \\
\text { concentrating }\end{array}$ & 0.778 & & & \\
\hline & Lack of energy & 0.657 & & & \\
\hline & Feeling nervous & 0.522 & & & \\
\hline & Feeling drowsy & 0.796 & & & \\
\hline & Difficulty sleeping & 0.561 & & & \\
\hline & Feeling sad & 0.613 & & & \\
\hline & Worrying & 0.701 & & & \\
\hline & Feeling irritable & 0.514 & & & \\
\hline & Pain & 0.725 & & & \\
\hline
\end{tabular}

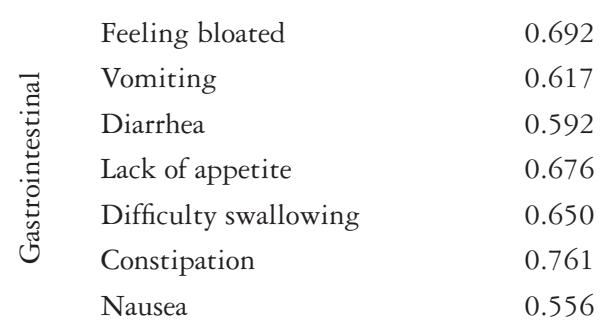

\begin{tabular}{|c|c|}
\hline $\begin{array}{l}\text { Numbness/tingling in } \\
\text { hands/feet }\end{array}$ & 0.758 \\
\hline $\begin{array}{l}\text { Problems with sexual } \\
\text { interest or activity }\end{array}$ & 0.640 \\
\hline $\begin{array}{l}\text { Change in the way } \\
\text { food tastes }\end{array}$ & 0.420 \\
\hline Weight loss & 0.759 \\
\hline Hair loss & 0.503 \\
\hline $\begin{array}{l}\text { "I don't look like } \\
\text { myself" }\end{array}$ & 0.594 \\
\hline Changes in skin & 0.610 \\
\hline
\end{tabular}

\begin{tabular}{|c|c|c|c|c|}
\hline Cough & & & & 0.413 \\
\hline Dry mouth & & & & 0.590 \\
\hline $\begin{array}{l}\text { Problems with } \\
\text { urination }\end{array}$ & & & & 0.580 \\
\hline Shortness of breath & & & & 0.534 \\
\hline Sweats & & & & 0.657 \\
\hline Itching & & & & 0.559 \\
\hline Dizziness & & & & 0.660 \\
\hline Mouth sores & & & & 0.556 \\
\hline $\begin{array}{l}\text { Swelling of arms or } \\
\text { legs }\end{array}$ & & & & 0.496 \\
\hline nvalue & 6.031 & 3.485 & 2.317 & 1.193 \\
\hline riance explained & 48.217 & 15.339 & 8.044 & 6.871 \\
\hline variance explained & 48.217 & 63.556 & 71.600 & 78.471 \\
\hline
\end{tabular}


common and significantly impact the quality of life of patients with CRC, once that influence your daily activities and hobbies, as well as social relationships. Although there are currently several forms of intervention (clinical and surgical) for the treatment of colorectal cancer, gastrointestinal symptoms - particularly nausea, vomiting, constipation and diarrhea-continue to be prominent in the course of the disease, either by frequency or by the potential for disability. that they generate in patients ${ }^{(28)}$. Importantly, in the general population, gastrointestinal symptoms represent about $10 \%$ of complaints in routine consultations, many of them due to chronic functional conditions, such as irritable bowel syndrome, chronic constipation and benign rectal lesions ${ }^{(29)}$. Because of this, the predictive value of symptoms for screening practice is not satisfactory. However, when summarized with other variables, especially demographic, such as gender and age; and with lifestyle characteristics, such as eating habits and physical inactivity, they can contribute more substantively, not only to early detection, but mainly to the prognosis and maintenance of quality of life.

In the end, as the clusters identified in this study are usually associated with quality of life predictors, their knowledge allows a more effective management of symptoms to improve the quality of life of cancer patients through the organization of appropriate care protocols for this population ${ }^{(23,24)}$. In this regard, Schouten et al. ${ }^{(30)}$, from a systematic review, highlighted the importance of the biopsychosocial impact of cancer and its treatment on the health and well-being of cancer patients. We assumed that the main focus of health care should be organized and patient-centered. Thus, it is necessary to create a more efficient therapeutic plan, even with limited health resources. Therefore, screening for psychosocial well-being and care needs encourages the detection of disorders and the referral of patients to specialized areas, contributing to the improvement of cancer patients' quality of life and making health care offered more efficient and effective.

Finally, it is important to highlight that there is no standardization of results and there is no clarity as to the content of interventions, such as instruments, procedures and conditions for implementation, which corroborates the heterogeneity found ${ }^{(30)}$. Similarly, Marventano et al. ${ }^{(23)}$ evidenced the heterogeneity of instruments and different statistical analyzes used, compromising the comparison between studies.

In practice, symptom clusters are used for three main reasons. First, they may warn of unfavorable outcomes in this population, such as depression, functional limitations, poor quality of life, and mortality. Second, since we established the clusters, the evaluation of symptoms is more complete, anticipating and preventing the appearance of other related symptoms. Third, recognizing the grouping of symptoms allows greater efficiency in the management of symptoms through a single therapeutic approach, avoiding a different approach for each symptom presented by the patient $t^{25,30)}$. Thus, it is necessary to carry out more studies with greater homogeneity and clarity in the methodology to allow the comparison between the studies. Still, it's important to get a sample big enough to study the cluster composition according to different type and phase of colon and rectal tumor, since they have different symptoms according to stage, for both prevalence and intensity.

\section{CONCLUSION}

The objective of the present study was to characterize the pattern of symptoms in patients with colorectal cancer. Our results are very similar to those found in other studies that evaluated patterns of symptoms in this population. We believe that the use of the instruments for symptoms evaluation seems to be useful not to manage the treatment of the disease, but to improve the quality of life.

\section{Authors' contribution}

Mello MRSP and Moura SF participated in the research execution, data collection and text writing. Guimarães RM and Muzi CD participated in the study design, statistical analysis, manuscript writing and final revision of the text.

\section{Oricid}

Marianne Regina Silva Potengy de Mello: 0000-0002-2121-5321.

Silmara Fernandes Moura: 0000-0001-9364-1656.

Camila Drumond Muzi: 0000-0002-5567-0437.

Raphael Mendonça Guimarães: 0000-0003-1225-6719.

Mello MRSP, Moura SF, Muzi CD, Guimarães RM. Avaliação clínica e padrão sintomatológico em pacientes com câncer colorretal. Arq Gastroenterol. 2020;57(2):131-6

RESUMO - Contexto - O câncer colorretal é o terceiro tipo de câncer mais comum no mundo e o aumento de sobrevida da população com câncer colorretal é muito significativo. Com isso, torna-se relevante o estudo dos sintomas associados à progressão da doença e do tratamento, para um manejo clínico adequado. Objetivo - Descrever o perfil clínico e epidemiológico de pacientes com câncer colorretal e identificar padrões de sinais e sintomas mais prevalentes. Métodos - Estudo transversal que avaliou prevalência de sintomas em 348 pacientes com câncer colorretal internados em hospital de referência em oncologia. Foi aplicada a escala MSAS-BR e, através da análise fatorial com análise dos componentes principais, realizou-se o agrupamento de sintomas. Resultados - Houve predomínio de homens, com 60 anos ou mais, casados, de cor branca, com o ensino médio, com tumor moderadamente diferenciado, doença com estágio III/IV, com câncer de cólon e sem metástase à distância. O sintoma mais prevalente foi perda de peso $(67,53 \%)$ e o menos prevalente foi ferida na boca $(2,01 \%)$. Os agrupamentos de sintomas formados foram "fadiga e sintomas psíquicos", "sintomas gastrointestinais", "sintomas autoperceptivos" e "sintomas gerais", que descreveram $80 \%$ dos sintomas apresentados. Conclusão - Evidenciou-se a importância da identificação desses sintomas para criação de estratégias de manejo clínico de pacientes com câncer colorretal.

DESCRITORES - Neoplasias colorretais. Avaliação de sintomas. Qualidade de vida. 


\section{REFERENCES}

1. Yiu AJ, Yiu CY. Biomarkers in Colorectal Cancer. Anticancer Res. 2016;36 1093-102.

2. Dutra VGP, Parreira VAG, Guimarães RM. Evolution of mortality for colorectal cancer in Brazil and regions, by sex, 1996-2015. Arq. Gastroenterol. 2018;55:61-5.

3. International Agency for Research on Cancer (IARC) Cancer Today: Colorecta cancer [Access 2019 January]. Available from: https://gco.iarc.fr/today/data/ factsheets/cancers/10_8_9-Colorectum-fact-sheet.pdf

4. Instituto Nacional de Câncer José Alencar Gomes da Silva (INCa). Estimativa 2018: incidência de câncer no Brasil. Rio de Janeiro, 2017.

5. Allemani C, Matsuda T, Di Carlo V, Harewood R, Matz M, Niksic M, et al. Global surveillance of trends in cancer survival 2000-14 (CONCORD-3): analysis of individual records for 37513025 patients diagnosed with one of 18 cancers from 332 population-based registries in 71 countries. Lancet. 2018;391:1023-75.

6. Roncucci L, Mariani F. Prevention of colorectal cancer: how many tools do we have in our basket? Eur J Intern Med. 2015;26:752-6.

7. Leggett BA, Hewett DG. Colorectal cancer screening. Intern Med J. 2015;45:6-15.

8. Saidi HS, Karuri D, Nyaim EO. Correlation of clinical data, anatomical site and disease stage in colorectal cancer. East Afr Med J. 2008;85:259.

9. Aktas A. Cancer symptom clusters: current concepts and controversies. Curr Opin Support Palliat Care. 2013;7:38-44.

10. Barsevick A. Defining the Symptom Cluster: How Far Have We Come? Semin Oncol Nurs. 2016;32:334-350.

11. Aktas A, Walsh D, Rybicki L. Symptom clusters: myth or reality? Palliat Med. 2010;24:373-85.

12. Kunitake H, Russell MM, Zheng P, Yothers G, Land SR, Petersen L, et al. Quality of life and symptoms in long-term survivors of colorectal cancer: results from NSABP protocol LTS-01. J Cancer Surviv. 2017;11:111-8.

13. Jefford M, Gough K, Drosdowsky A, Russell L, Aranda S, Butow P, et al. A Randomized Controlled Trial of a Nurse-Led Supportive Care Package (SurvivorCare) for Survivors of Colorectal Cancer. Oncologist. 2016;21:1014-23.

14. Cabilan CJ, Hines S. The short-term impact of colorectal cancer treatment on physical activity, functional status and quality of life: a systematic review. JBI Database System Rev Implement Rep. 2017;15:517-566.

15. Menezes JR, Luvisaro BMO, Rodrigues CF, Muzi CD, Guimarães RM. Confiabilidade teste-reteste da versão Brasileira do instrumento Memorial Symptom Assessment Scale para avaliação de sintomas em pacientes oncológicos. Einstein. $2017 ; 15: 148-54$

16. Rocha LF, Carvalho MS, Lacerda AAML, Viana AFV, Ramos RS, Guimarães RM, et al. Equivalência semântica da versão em português do instrumento Memorial Symptom Assessment Scale (MSAS) para avaliar sintomas em pacientes oncológicos. Rev. Bras. Pesq. Saúde. 2017;19:83-91.
17. Mingoti, SA. Análise de Dados Através de Métodos de Estatística Multivariada: uma abordagem aplicada. Belo Horizonte: Editora UFMG; 2005.

18. Wilson, M. Constructing measures. An item response modeling approach. Mahwah, NJ: Lawrence Erlbaum Associates, Publishers; 2005.

19. O'Gorman C, Stack J, O'Ceilleachair A, Denieffe S, Gooney M, McKnight M, Sharp L. Colorectal cancer survivors: an investigation of symptom burden and influencing factors. BMC Cancer. 2018;18:1022.

20. Dong ST, Costa DS, Butow PN, Lovell MR, Agar M, Velikova G, et al. Symptom Clusters in Advanced Cancer Patients: An Empirical Comparison of Statistical Methods and the Impact on Quality of Life. Journal of Pain and Symptom Management. 2016;51:88-98.

21. Omran S, Khader Y, McMillan S. Symptom Clusters and Quality of Life in Hospice Patients with Cancer. Asian Pac J Cancer Prev. 2017;18:2387-93.

22. Mattsson S, Olsson EMG, Carlsson M, Johansson BBK. Identification of Anxiety and Depression Symptoms in Patients With Cancer: Comparison Between Short and Long Web-Based Questionnaires. J Med Internet Res. 2019;21:e11387.

23. Marventano S, Forjaz M, Grosso G, Mistretta A, Giorgianni G, Platania A, et al. Health related quality of life in colorectal cancer patients: state of the art. BMC Surg. 2013;13 (Suppl 2):S15.

24. Lavdaniti M, Fradelos EC, Troxoutsou K, Zioga E, Mitsi D, Alikari V, Zyga S Symptoms in Advanced Cancer Patients in a Greek Hospital: a Descriptive Study. Asian Pac J Cancer Prev. 2018;19:1047-52.

25. Naik AD, Uy N, Anaya DA, Moye J. The effects of age, education, and treatment on physical, sexual and body concern symptoms among multimorbid, colorectal cancer survivors. J Geriatr Oncol. 2015;6:299-306.

26. Peng YN, Huang ML, Kao CH. Prevalence of Depression and Anxiety in Colorectal Cancer Patients: A Literature Review. Int J Environ Res Public Health. 2019;16(3).

27. Agasi-Idenburg SC, Thong MS, Punt CJ, Stuiver MM, Aaronson NK. Comparison of symptom clusters associated with fatigue in older and younger survivors of colorectal cancer. Support Care Cancer. 2017;25:625-32.

28. Rangwala F, Zafar SY, Abernethy AP. Gastrointestinal symptoms in cancer patients with advanced disease: new methodologies, insights, and a proposed approach. Curr Opin Support Palliat Care. 2012;6:69-76.

29. Vega P, Valentín F, Cubiella J. Colorectal cancer diagnosis: Pitfalls and opportunities. World J Gastrointest Oncol. 2015;7:422-33.

30. Schouten B, Avau B, Bekkering GTE, Vankurunkelsven P, Mebis J, Helling J, et al. Systematics screening and assessment of psychosocial well-being and care needs of people with cancer. Cochrane Database Syst Rev. 2019;3:CD012387. 